\title{
Demodex Species Frequency and Risk Factors in Patients With Rheumatoid Arthritis
}

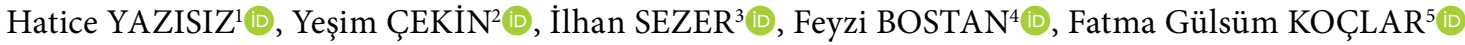 \\ ${ }^{1}$ Department of Medical Microbiology, Division of Parasitology, Akdeniz University Faculty of Medicine, Antalya, Turkey \\ ${ }^{2}$ Department of Medical Microbiology, University of Health Sciences, Antalya Training and Research Hospital, Antalya, Turkey \\ ${ }^{3}$ Department of Physical Therapy and Rehabilitation, Division of Rheumatology University of Health Sciences, \\ Antalya Training and Research Hospital, Antalya, Turkey \\ ${ }^{4}$ Department of Internal Medicine, University of Health Sciences, Antalya Training and Research Hospital, Antalya, Turkey \\ ${ }^{5}$ Department of Medical Parasitology, University of Health Sciences, Antalya Training and Research Hospital, Antalya, Turkey
}

\begin{abstract}
Objectives: This study aims to investigate the presence of Demodex species in rheumatoid arthritis (RA) patients, to identify the risk factors for developing Demodex infestation, and to determine the effect of immunosuppressant drugs on Demodex mite infestations.

Patients and methods: The study included 93 RA patients ( 16 males, 77 females; mean age $53.3 \pm 11.3$ years; range, 27 to 83 years) and 76 healthy controls ( 19 males, 57 females; mean age $50.3 \pm 13.9$ years; range, 19 to 86 years). Specimens were collected from face skin by using standardized surface skin biopsy. Demodex infestation was considered for $\geq 5$ living parasites $/ \mathrm{cm}^{2}$ of skin while Demodex mite presence was defined as any Demodex larvae, adults, or eggs found in the specimen.

Results: The frequencies of Demodex mite presence were $44 \%$ for the RA patients and $15.7 \%$ for the healthy controls ( $p<0.001$ ). The rates of Demodex infestation were similar between the two groups ( $18.3 \%$ versus $7.9 \%, p=0.054)$. There were no statistically significant differences between the groups regarding skin type, skin care, epilation, body washing, use of a moisturizer, personal towel use, the number of residents at home, or whether there were pets at home or in proximity. Itching in eyes was higher in RA patients, but the frequency of other skin symptoms was not different from healthy controls. Logistic regression analysis indicated that the diagnosis of RA was an independent risk factor for Demodex mite presence in this study population. Disease activity and duration, use of corticosteroids, conventional disease-modifying anti-rheumatic drugs (DMARDs) and biological DMARDs were not effective factors on Demodex mite presence in RA patients.

Conclusion: Although Demodex mite presence was 3.5-fold higher in RA patients, the rate of Demodex infestation was similar to that of healthy controls.

Keywords: Biological disease-modifying anti-rheumatic drugs, conventional disease-modifying anti-rheumatic drugs, Demodex folliculorum, infestation, mite, rheumatoid arthritis.
\end{abstract}

Demodex mites are permanent ectoparasites in mammalian pilosebaceous units. Although 140 species of Demodex have been identified in mammals, Demodex brevis (D. brevis) and Demodex folliculorum (D. folliculorum) have been found in humans. ${ }^{1}$ These species occupy different glands in the skin: D. folliculorum is found in the follicles of simple hairs above the level of the sebaceous glands, whereas $D$. brevis is found in the sebaceous glands of the vellus hairs. ${ }^{2}$

Demodex infestation can be detected in healthy individuals, and its incidence increases with age. ${ }^{1,3}$ The pathogenic potential of Demodex species in animals has been demonstrated; in humans, they can become harmful to the host as opportunistic pathogens in the immunosuppressive cases. ${ }^{4}$

Received: July 02, 2019 Accepted: November 02, 2019 Published online: February 07, 2020

Correspondence: Hatice Yazısız, MD. Akdeniz Üniversitesi Tıp Fakültesi Tıbbi Mikrobiyoloji Anabilim Dalı, Parazitoloji Bilim Dalı, 07070 Konyaaltı, Antalya, Türkiye. Tel: +90 505 - 3149901 e-mail: drhyazisiz@yahoo.com.tr

\section{Citation:}

Yazısız H, Çekin Y, Sezer I, Bostan F, Koçlar FG. Demodex Species Frequency and Risk Factors in Patients with Rheumatoid Arthritis. Arch Rheumatol 2020;35(3):376-384. 
The relationship between Demodex species and the immune system remains unclear, and controversies and research on the pathogenesis of Demodex-related skin diseases continue. ${ }^{5}$ Clinical studies have investigated the effect of immunosuppression on Demodex infestation, ${ }^{6}$ which has been shown to be high in hematological malignancies treated with chemotherapy. ${ }^{7}$ In a study by Kaya et al., ${ }^{8}$ demodex mites were found more often in patients with sickle cell anemia which is a compromised immune system.

Rheumatoid arthritis (RA) is an autoimmune disease characterized by persistent arthritis and systemic inflammation. RA affects more females than males, with an estimated prevalence of $0.5-1 \%$ in adults. The international recommendations for the treatment of RA include glucocorticoids; conventional disease-modifying anti-rheumatic drugs (cDMARDs), mainly methotrexate; and biological DMARDs (bDMARDs), such as antitumor necrosis factors, anti-interleukin-6, and anti-CD20. Patients with RA typically exhibit immune dysregulation and a predisposition to infections. Furthermore, drugs used to treat RA are immunosuppressive, and it was reported that the frequency of tuberculosis and opportunistic infections increased in RA patients treated with biological agents. ${ }^{9}$

Preliminary studies were conducted to estimate the prevalence of Demodex mites in RA patients. ${ }^{10,11}$ In these studies, the number of patients was relatively low. Furthermore, the results of preliminary studies need verification. Therefore, in this study, we aimed to investigate the presence of Demodex species in RA patients, to identify the risk factors for developing Demodex infestation, and to determine the effect of immunosuppressant drugs on Demodex mite infestations.

\section{PATIENTS AND METHODS}

The study sample consisted of 93 patients with RA (16 males, 77 females; mean age 53.3 \pm 11.3 years; range, 27 to 83 years), who fulfilled the 2010 European League Against Rheumatism and the American College of Rheumatology criteria, ${ }^{12}$ and 76 healthy controls (19 males, 57 females; mean age $50.3 \pm 13.9$ years; range, 19 to 86 years). The RA patients included in this study were treated and followed-up at the rheumatology outpatient clinic of Antalya Training and Research Hospital between June 2017 and December 2018. The healthy control group consisted of volunteers who were checked from the department of internal medicine. Consecutive individuals without any systemic disease formed the healthy control group. Demographic characteristics of control individuals were similar to the RA patients. Exclusion criteria were patients with an autoimmune disease other than RA, chronic diseases associated with immune deficiency, diabetes mellitus, or any immunosuppressive drug use. The study protocol was approved by the Antalya Training and Research Hospital Ethics Committee (date: 05/09/2017, approval number: 12/08). A written informed consent was obtained from each participant. The study was conducted in accordance with the principles of the Declaration of Helsinki.

A questionnaire was administered to ask the participants about the risk factors for Demodex mite presence. Samples were taken from the face area (i.e., cheeks, nose, chin, or forehead) by using a standard superficial skin biopsy (SSSB) method. SSSB was preferred particularly in areas with skin lesions such as redness or acne. The patients' faces were cleaned with alcohol (to remove any residual cream or lotion) and allowed to air dry. A drop of cyanoacrylic adhesive was placed on a microscope slide before applying the slide to

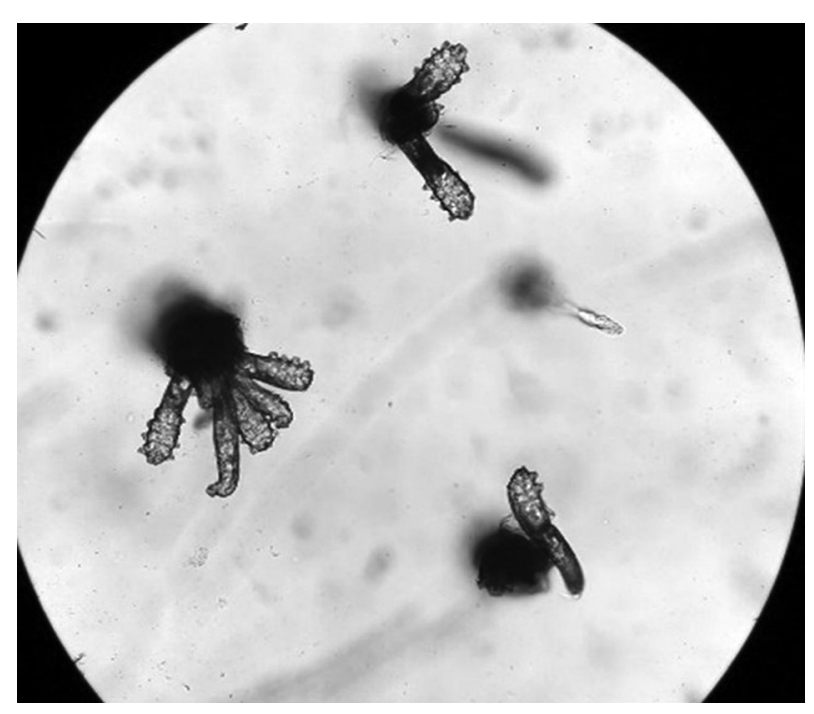

Figure 1. Demodex species on a sample from skin by using a standard superficial skin biopsy method. 
Table 1. Clinical characteristics of patients with rheumatoid arthritis and healthy controls

\begin{tabular}{|c|c|c|c|c|c|c|c|}
\hline & \multicolumn{3}{|c|}{ RA patients $(n=93)$} & \multicolumn{3}{|c|}{ Healthy controls $(n=76)$} & \multirow[b]{2}{*}{$p$} \\
\hline & $\mathrm{n}$ & $\%$ & Mean \pm SD & $\mathrm{n}$ & $\%$ & Mean \pm SD & \\
\hline Age (year) & & & $53.3 \pm 11.3$ & & & $50.3 \pm 13.9$ & 0.119 \\
\hline Disease duration (month) & & & $90.5 \pm 66.7$ & & & - & - \\
\hline DAS28 & & & $2.9 \pm 1.0$ & & & - & - \\
\hline $\begin{array}{l}\text { Sex } \\
\quad \text { Female }\end{array}$ & 77 & 82.8 & & 57 & 75.0 & & 0.213 \\
\hline $\begin{array}{l}\text { Disease activity } \\
\text { Remission (DAS28 } \leq 2.6 \text { ) } \\
\text { Low (DAS28 2.6-3.2) } \\
\text { Moderate (DAS28 3.2-5.1) } \\
\text { High (DAS28 } \geq 5.1 \text { ) }\end{array}$ & $\begin{array}{c}46 \\
34 \\
8 \\
5\end{array}$ & $\begin{array}{c}49.5 \\
36.6 \\
8.6 \\
5.4\end{array}$ & & $\begin{array}{l}- \\
- \\
-\end{array}$ & $\begin{array}{l}- \\
- \\
- \\
-\end{array}$ & & $\begin{array}{l}- \\
- \\
-\end{array}$ \\
\hline $\begin{array}{l}\text { Drugs } \\
\text { Corticosteroids } \\
\text { Conventional (cDMARDs) } \\
\text { Methotrexate } \\
\text { Hydroxychloroquine } \\
\text { Sulfosalazine } \\
\text { Leflunomide } \\
\text { Biologic (bDMARDs) }\end{array}$ & $\begin{array}{c}57 \\
\\
77 \\
31 \\
9 \\
11 \\
14\end{array}$ & $\begin{array}{c}61.3 \\
\\
82.2 \\
33.3 \\
9.7 \\
11.8 \\
15.1\end{array}$ & & $\begin{array}{l}- \\
- \\
- \\
- \\
-\end{array}$ & $\begin{array}{l}- \\
- \\
- \\
- \\
-\end{array}$ & & $\begin{array}{l}- \\
- \\
- \\
- \\
-\end{array}$ \\
\hline $\begin{array}{l}\text { Lifestyle } \\
\text { Epilation* } \\
\text { Make-up* } \\
\text { Presence of pet* } \\
\text { Common towel use } \\
\text { Use of a moisturizer* } \\
\text { Skin care }\end{array}$ & $\begin{array}{c}4 \\
6 \\
12 \\
40 \\
16 \\
1\end{array}$ & $\begin{array}{c}4.6 \\
6.8 \\
13.6 \\
45.5 \\
18.2 \\
1.13\end{array}$ & & $\begin{array}{c}4 \\
7 \\
13 \\
42 \\
14 \\
4\end{array}$ & $\begin{array}{c}5.6 \\
9.6 \\
17.8 \\
57.6 \\
19.2 \\
5.6\end{array}$ & & $\begin{array}{l}0.799 \\
0.524 \\
0.534 \\
0.174 \\
0.678 \\
0.118\end{array}$ \\
\hline $\begin{array}{l}\text { Skin type } \\
\text { Oily } \\
\text { Dry } \\
\text { Combination }\end{array}$ & $\begin{array}{l}21 \\
37 \\
30\end{array}$ & $\begin{array}{l}23.9 \\
42.0 \\
34.1\end{array}$ & & $\begin{array}{l}13 \\
34 \\
26\end{array}$ & $\begin{array}{l}17.6 \\
46.6 \\
35.6\end{array}$ & & 0.617 \\
\hline $\begin{array}{l}\text { The number of residents at home } \\
1-2 \text { person } \\
3-4 \text { person } \\
\geq 5 \text { person }\end{array}$ & $\begin{array}{l}34 \\
44 \\
15\end{array}$ & $\begin{array}{l}36.6 \\
47.3 \\
16.1\end{array}$ & & $\begin{array}{l}21 \\
35 \\
20\end{array}$ & $\begin{array}{l}27.6 \\
46.0 \\
26.3\end{array}$ & & 0.209 \\
\hline $\begin{array}{l}\text { Body washing } \\
1-2 \text { times/week } \\
3-4 \text { times/week } \\
\geq 5 \text { times/week }\end{array}$ & $\begin{array}{l}18 \\
38 \\
37\end{array}$ & $\begin{array}{l}19.4 \\
40.9 \\
39.8\end{array}$ & & $\begin{array}{l}23 \\
32 \\
21\end{array}$ & $\begin{array}{l}30.3 \\
42.1 \\
27.6\end{array}$ & & 0.145 \\
\hline $\begin{array}{l}\text { Symptoms } † \\
\text { Skin redness } \\
\text { Acne }\end{array}$ & $\begin{array}{l}35 \\
17\end{array}$ & $\begin{array}{l}39.7 \\
19.3\end{array}$ & & $\begin{array}{l}20 \\
19\end{array}$ & $\begin{array}{l}27.0 \\
25.7\end{array}$ & & $\begin{array}{l}0.120 \\
0.352\end{array}$ \\
\hline $\begin{array}{l}\text { Itching } \\
\text { Eyes } \\
\text { Ears } \\
\text { Face }\end{array}$ & $\begin{array}{l}40 \\
29 \\
20\end{array}$ & $\begin{array}{l}45.5 \\
37.8 \\
22.7\end{array}$ & & $\begin{array}{l}22 \\
28 \\
17\end{array}$ & $\begin{array}{l}29.7 \\
37.8 \\
22.9\end{array}$ & & $\begin{array}{r}\mathbf{0 . 0 4 0} \\
0.517 \\
0.998\end{array}$ \\
\hline $\begin{array}{l}\text { Demodex mite presence } \\
\text { Demodex folliculorum } \\
\text { Demodex brevis } \\
\text { Demodex species }\end{array}$ & $\begin{array}{c}41 \\
26 \\
7 \\
8\end{array}$ & $\begin{array}{c}44.1 \\
27.9 \\
7.5 \\
8.6\end{array}$ & & $\begin{array}{l}12 \\
8 \\
2 \\
2\end{array}$ & $\begin{array}{l}15.7 \\
10.5 \\
2.6 \\
2.6\end{array}$ & & $\begin{array}{c}<\mathbf{0 . 0 0 1} \\
\mathbf{0 . 0 0 6} \\
0.188 \\
0.278\end{array}$ \\
\hline Demodex infestation ( $\geq 5$ Demodex $/ \mathrm{cm}^{2}$ ) & 17 & 18.3 & & 6 & 7.9 & & 0.054 \\
\hline $\begin{array}{l}\text { Semiquantitative score } \\
\qquad\left(<5 \text { Demodex } / \mathrm{cm}^{2}\right)(+) \\
\left(5-10 \text { Demodex } / \mathrm{cm}^{2}\right)(++) \\
\left(>10 \text { Demodex } / \mathrm{cm}^{2}\right)(+++)\end{array}$ & $\begin{array}{c}24 \\
10 \\
7\end{array}$ & $\begin{array}{c}25.8 \\
10.8 \\
7.6\end{array}$ & & $\begin{array}{l}6 \\
3 \\
3\end{array}$ & $\begin{array}{l}7.9 \\
3.9 \\
3.9\end{array}$ & & 0.807 \\
\hline
\end{tabular}

RA: Rheumatoid arthritis; SD: Standard deviation; DAS28: Disease activity score 28; cDMARDs: Conventional disease-modifying antirheumatic drugs; bDMARDs: Biological disease-modifying anti-rheumatic drugs; * Eighty-eight rheumatoid arthritis patients and 73 healthy controls were included in the analysis; $†$ Eighty-eight rheumatoid arthritis patients and 74 healthy controls were included in the analysis. 
the skin surface. After approximately one minute, the slide was slowly removed. After a few drops of immersion oil material was applied to each slide, it was microscopically examined by a parasitology specialist at $\times 10$ and $\times 40$ objectives. Demodex mites are shown in Figure 1. D. folliculorum and D. brevis were distinguished by their apparent morphological features, as described by Akbulatova. ${ }^{13}$ The number of parasites was evaluated using a semiquantitative scoring system: fewer than five (+), five-10 (++) and more than $10(+++)$ mites $/ \mathrm{cm}^{2}$ of skin. Demodex infestation was considered for $\geq 5$ living mites $/ \mathrm{cm}^{2}$; while Demodex mite presence was defined as any Demodex larvae, adults, or eggs found in the specimen.

\section{Statistical analysis}

Statistical analysis was performed using the SPSS for Windows version 13.0 software (SPSS
Inc., Chicago, IL, USA). Descriptive statistics was used to evaluate the characteristics of the study groups, and Chi-square and Fisher's exact tests were conducted to compare the categorical differences between the groups. The significance of differences was analyzed using Student's t test. Logistic regression was performed to ascertain the risk factors for Demodex mite presence, and $p<0.05$ was considered statistically significant.

\section{RESULTS}

The distribution of sexes was similar between the groups $(p=0.213)$. The frequencies of clinical symptoms about Demodex mites, except itching in the eyes, were similar among groups. The questionnaire results yielded no statistically significant difference between the groups regarding

Table 2. Comparison of rheumatoid arthritis patients with and without Demodex mite presence and Demodex infestation

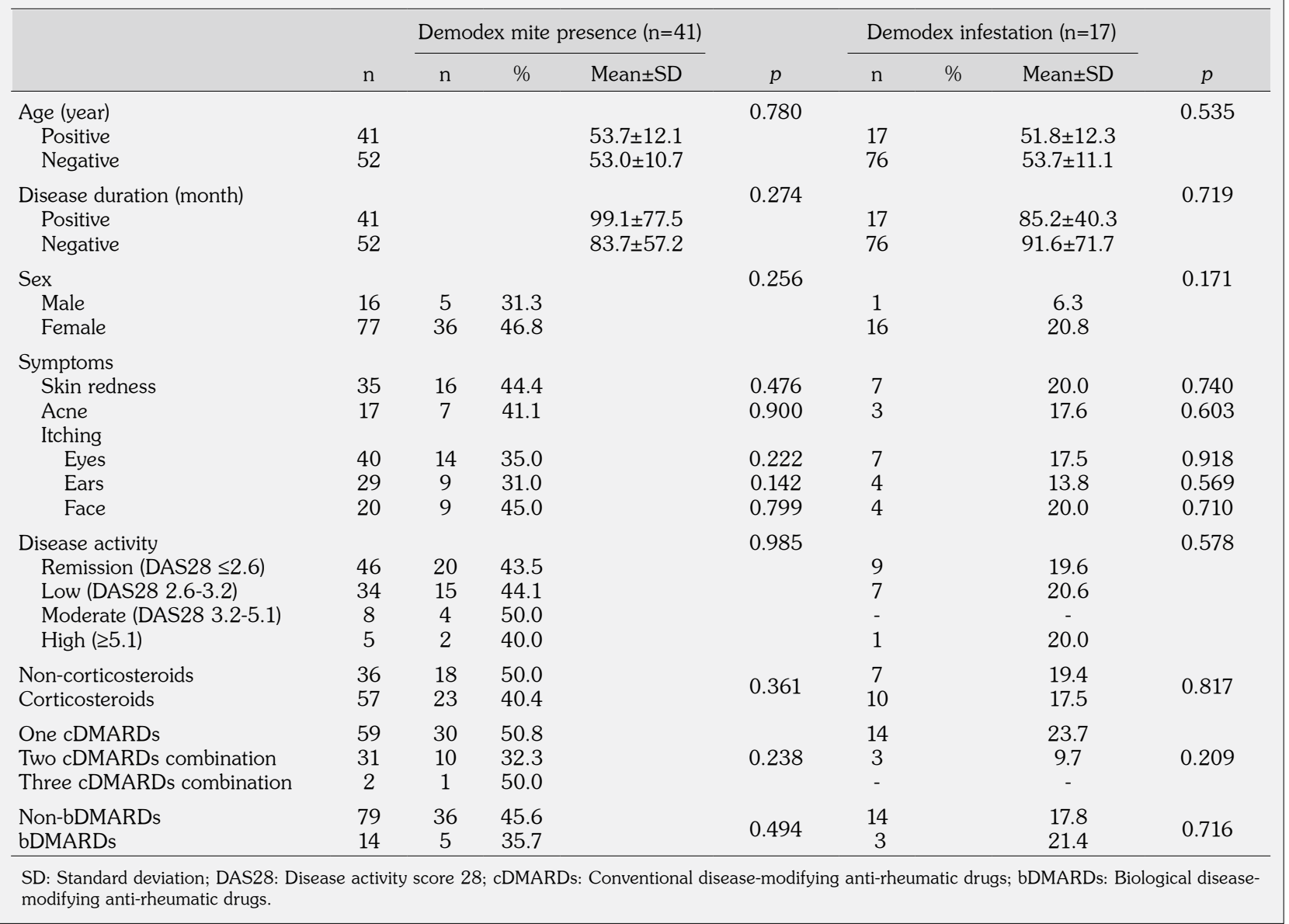




\begin{tabular}{|c|c|c|c|}
\hline & Odds ratio & $95 \% \mathrm{CI}$ & $p$ \\
\hline \multicolumn{4}{|l|}{ All of cohort $(n=169)$} \\
\hline Rheumatoid arthritis & 3.491 & $1.466-8.310$ & 0.005 \\
\hline Living region & 1.259 & $0.754-2.103$ & 0.379 \\
\hline Bath number/week & 1.137 & $0.846-1.530$ & 0.395 \\
\hline Skin color & 1.245 & 0.779-1.991 & 0.360 \\
\hline Skin type & 0.883 & $0.426-1.485$ & 0.640 \\
\hline Cream use & 1.634 & $0.594-4.500$ & 0.342 \\
\hline Make-up & 0.318 & $0.051-1.914$ & 0.211 \\
\hline Pet at home & 1.469 & $0.496-4.351$ & 0.487 \\
\hline Pet in proximity & 0.309 & $0.079-1.209$ & 0.091 \\
\hline Personal towel use & 0.742 & $0.342-1.609$ & 0.450 \\
\hline Number of residents ( $>50$ years old) & 0.578 & 0.260-1.019 & 0.187 \\
\hline \multicolumn{4}{|l|}{ Rheumatoid arthritis $(n=93)$} \\
\hline Corticosteroids use & 0.725 & $0.294-1.789$ & 0.485 \\
\hline Methotrexate use & 1.227 & $0.235-6.411$ & 0.809 \\
\hline Leflunomide use & 0.447 & $0.055-3.627$ & 0.451 \\
\hline Hydroxychloroquine use & 0.657 & 0.253-1.709 & 0.389 \\
\hline Sulfasalazine use & 1.420 & $0.319-6.314$ & 0.645 \\
\hline bDMARDs use & 0.629 & $0.174-2.271$ & 0.479 \\
\hline Disease duration & 1.004 & 0.998-1.011 & 0.195 \\
\hline Disease activity & 0.957 & $0.603-1.521$ & 0.853 \\
\hline \multicolumn{4}{|c|}{ bDMARDs: Biological disease-modifying anti-rheumatic drugs; CI: Confidence interval. } \\
\hline
\end{tabular}

skin type, skin care, epilation, body washing, use of a moisturizer, personal towel use, the number of residents at home, or whether there were pets at home or in proximity. All RA patients were using at least one cDMARD. The used drugs, rheumatoid factor and anti-cyclic citrullinated peptide positivity, disease activity and disease duration of RA patients are shown in Table 1.

Microscopic examination revealed that the frequencies of Demodex mite presence were 44\% $(n=41 / 93)$ for the RA patients and $15.7 \%$ for the healthy controls $(n=12 / 76)$, with a statistically significant difference $(p<0.001)$. D. folliculorum was significantly higher in RA patients $(p=0.006)$, unlike the other Demodex species. The rates of Demodex infestation were similar between the groups (18.3\% vs. $7.9 \%, p=0.054)$. D. folliculorum was detected in $34 \mathrm{RA}$ patients and 10 healthy controls, while $D$. brevis was observed in seven RA patients and two healthy controls. The results of microscopic examination are also summarized in Table 1.
We compared some features of RA patients to detect any effect on Demodex mite presence and Demodex infestation. Age, sex, disease duration, disease activity and treatment agents such as corticosteroids, cDMARDs and bDMARDs were found to have no effect on Demodex mite presence or Demodex infestation. There was no correlation between the number of drugs used and Demodex species in RA patients Also, the frequencies of skin symptoms were not significantly different from RA patients without Demodex species (Table 2).

Logistic regression analysis was performed to determine the factors on Demodex positivity, which revealed that the diagnosis of RA was an independent risk factor for Demodex mite presence in the study population (odds ratio $[\mathrm{OR}]=3.491,95 \%$ confidence interval $[\mathrm{CI}]$ : 1.466-8.310, $\mathrm{p}=0.005)$. However, there was no decisive factor determining the presence of Demodex mites in RA patients (Table 3). 


\section{DISCUSSION}

Demodex mites are prevalent in many human skin disorders, and their pathogenic role continues to be debated. ${ }^{1}$ In the skin flora, fewer than five mites $/ \mathrm{cm}^{2}$ is considered normal, whereas the presence of more than five mites indicates a positive diagnosis of demodicosis. ${ }^{14-17}$ Demodex infestation can be detected in healthy individuals (total infestation rate $=17 \%-72 \%$ ) and the incidence increases with age, affecting $100 \%$ of people over the age of 96 years. ${ }^{1,18}$ Also, some authors have claimed that Demodex mites are symbiotic inhabitants and can be a part of the microbiome within human skin. ${ }^{19}$

The results of this study have shown that Demodex mite presence (i.e., D. folliculorum and/or D. brevis) was higher in RA patients than healthy controls (44\% vs. $15.7 \%$ ). However, the rates of Demodex infestation ( $\geq 5$ mites $/ \mathrm{cm}^{2}$ of skin) were $18.3 \%$ for the RA patients and $7.9 \%$ for the healthy controls, with no statistically significant difference between the groups. In previous studies, the prevalence of Demodex mites in RA patients has not been statistically significantly different from that in healthy controls. ${ }^{10,11}$ This difference in study results may be attributed to several factors, such as age, sex, and the number of patients. In addition, the mite detection methods used in the cited studies may have affected the results. Çiftçi et al. ${ }^{10}$ have reported that the prevalence of $D$. folliculorum infestation was $12 \%$ and $8 \%$ in their RA and control groups, respectively, and that there was no statistically significant difference between the groups in the density or incidence of Demodex. They considered $\geq 5$ mites $/ \mathrm{cm}^{2}$ of skin as a positivity criterion. The results of our study support those of previous research regarding the prevalence of Demodex infestation. In a study conducted in Poland, the mean age was 61 years; $33 \%$ of patients in the RA group and $31 \%$ of the control group were found to be positive for Demodex infestation, with no statistically significant difference between the groups $(p=0.98) .{ }^{11}$ In the cited study, eyelashes were epilated to find mites and a positive result was recorded if any Demodex larvae, adults, or eggs were found. Although their study population and methods were different from those of our study, their results were similar to ours.
Our study has found Demodex infestation in $7.9 \%(n=6)$ of the healthy controls. Several studies have reported on the prevalence of Demodex species in the Turkish population. ${ }^{20-29}$ Demodex species positivity was found in $6.7-74.7 \%$ of the healthy Turkish population living in various regions. ${ }^{20-29}$ There may be several reasons for the differences among regions and many other factors may influence the prevalence of Demodex mite presence. It has been stated that the number of parasites increases, particularly in the summer months, with an increase in environmental temperature; this may occur through the seasonal activation of sebum production. ${ }^{30}$ It was suggested that the high prevalence of Demodex mites in Brazil may be due to the humid subtropical climate. ${ }^{31}$ In our study region, the summer season is quite long, with high temperature and humidity. In both the RA patients and healthy controls, the prevalence of Demodex mites was the same as those in patients from other cities in Turkey, even in the Antalya region.

Several methods are used for defining Demodex, such as the cellophane tape method, squeezing method, skin scraping, SSSB, eyelash epilation, comedone extraction, skin punch biopsy, extraction from acne through compression methods, dermoscopy, reflectance confocal microscopy, and confocal laser scanning microscopy. SSSB is the most commonly used method for comparing mite densities between patients and healthy controls. SSSB is a noninvasive and standardized method that enables determining the number of Demodex mites $/ \mathrm{cm}^{2}$ of skin. It is often painless and easily tolerated by the patient, even if the sample is removed from the contents of the upper pilosebaceous canals. ${ }^{1,5,32,33}$ Likewise, in our study, we examined the skin by using SSSB to determine the number of mites $/ \mathrm{cm}^{2}$ (Table 1). Demodex mite presence was higher in RA patients than in healthy controls. The results of regression analysis showed that RA patients had a 3.5-fold increased risk of Demodex mite presence (OR: 3.491, 95\% CI: 1.466-8.310, $\mathrm{p}=0.005$ ). However, the rates of Demodex infestation and numbers of parasites on the skin were no different than those for the healthy controls. Based on our study findings, Demodex species can be easily located in the follicles of RA patients, while their spread and multiplication are not affected by RA. Further studies are necessary to explain the 
spread factors that may be related to hosts and parasites regarding RA patients.

Most people exhibit the presence of Demodex mites without any clinical symptoms. Human demodicosis can be influenced by various factors, one of which is the immune system; immunosuppressed patients are particularly susceptible to such infections. ${ }^{8,34}$ Furthermore, it has been claimed that the increased incidence of $D$. folliculorum in patients with immunosuppression is associated with systemic illnesses, such as hematologic malignancies, acquired immunodeficiency syndrome, and diabetes mellitus. ${ }^{34-36}$ A previous study has reported that Demodex mites were observed more often in sickle cell anemia patients; in addition, authors have claimed that there was a relationship between the appearance of sickle cell anemia symptom attacks and the presence of Demodex mites. ${ }^{8}$ Anti-rheumatic drugs are commonly used in the management of RA, and most of them have immunosuppressive effects. Increased rates of infections are reported in patients with RA treated with steroids, methotrexate, leflunomide, and biological drugs. ${ }^{37}$ In our study, no relationship was found between the presence of Demodex mites and drugs, including corticosteroids, cDMARDs and bDMARDs.

Rheumatoid arthritis is mainly an autoimmune disease of the joints. However, it is not merely a joint disorder but also a systemic disease capable of involving a variety of major organ systems. Cutaneous manifestations related to RA are as follows: rheumatoid nodules; rheumatoid vasculitis; livedo racemosa; neutrophilic and/or granulomatous diseases, such as pyoderma gangrenosum; Sweet's syndrome; rheumatoid neutrophilic dermatitis; interstitial granulomatous dermatitis with arthritis; and palisaded neutrophilic and granulomatous dermatitis. ${ }^{38}$ The etiopathogenesis of skin lesions remains unclear and may be related to immune changes in the pathogenesis of RA. The presence of Demodex mites was not associated with skin lesions in our RA patients.

The damage in the RA-affected joints cause disability and further inconvenience in patients' daily activities. It is suggested that age, physical function, and social support were correlated significantly with self-care behavior. ${ }^{39}$ There is a negative relationship between disease severity and quality of life in RA patients. ${ }^{40}$ Advanced disease and limitations of joint movements may cause insufficiency in personal care in RA patients. The relationship between the presence of Demodex species and personal hygiene ability in patients with RA can be speculated. We did not evaluate the physical functions of the patients; we evaluated the number of baths per week that can reflect the functional status and personal hygiene of the patients. There was no relationships between Demodex presence and the number of baths per week. Besides, our previous study has shown no correlation between Demodex infestations and body hygiene. ${ }^{41}$

Our study has some limitations. Firstly, SSSB was obtained only from face skin, and the other skin areas were not investigated and compared for Demodex mite presence. Secondly, the power of some statistical analysis, such as the effects of bDMARDs on Demodex mite presence, were not enought to comment. Thirdly, a disease control group receiving a similar profile of immunosuppressant drugs was not included in this study.

In conclusion, this study has revealed that while RA patients had a 3.5-fold increased risk of Demodex mite presence, treatment agents, disease duration and activity were not found to be independent risk factors for Demodex positivity in RA patients.

\section{Declaration of conflicting interests}

The authors declared no conflicts of interest with respect to the authorship and/or publication of this article.

\section{Funding}

The authors received no financial support for the research and/or authorship of this article.

\section{REFERENCES}

1. Litwin D, Chen W, Dzika E, Korycinska J. Human Permanent Ectoparasites; Recent Advances on Biology and Clinical Significance of Demodex Mites: Narrative Review Article. Iran J Parasitol 2017;12:12-21.

2. Desch C, Nutting WB. Demodex folliculorum (Simon) and D. brevis akbulatova of man: redescription and reevaluation. J Parasitol 1972;58:169-77. 
3. Elston CA, Elston DM. Demodex mites. Clin Dermatol 2014;32:739-43.

4. Lacey N, Ní Raghallaigh S, Powell FC. Demodex mites-commensals, parasites or mutualistic organisms? Dermatology 2011;222:128-30.

5. Lacey N, Russell-Hallinan A, Powell FC. Study of demodex mites: Challenges and solutions. J Eur Acad Dermatol Venereol 2016;30:764-75.

6. Kosik-Bogacka DI, Lanocha N, Lanocha A, Czepita D, Grobelny A, Zdziarska B, et al. Demodex folliculorum and Demodex brevis in healthy and immunocompromised patients. Ophthalmic Epidemiol 2013;20:159-63.

7. Seyhan ME, Karincaoğlu Y, Bayram N, Aycan O, Kuku I. Density of Demodex folliculorum in haematological malignancies. J Int Med Res 2004;32:411-5.

8. Kaya OA, Akkucuk S, Ilhan G, Guneri CO, Mumcuoglu K. The Importance of Demodex Mites (Acari: Demodicidae) in Patients With Sickle Cell Anemia. J Med Entomol 2019;56:599-602.

9. Scott DL, Wolfe F, Huizinga TW. Rheumatoid arthritis. Lancet 2010;376:1094-108.

10. Ciftci IH, Dundar U, Cetinkaya Z, Kulac M, Kiyildi N, Turel A, et al. Demodex folliculorum in patients with rheumatoid arthritis. Acta Parasitologica 2007;52:70-3.

11. Garbacewicz A, Jaworski J, Grytner-Ziecina B. Demodex mite infestation in patients with and without rheumatoid arthritis. Acta Parasitol 2012;57:99-100.

12. Aletaha D, Neogi T, Silman AJ, Funovits J, Felson DT, Bingham CO 3rd, et al. 2010 rheumatoid arthritis classification criteria: an American College of Rheumatology/European League Against Rheumatism collaborative initiative. Ann Rheum Dis 2010;69:1580-8.

13. Akbulatova L. Demodicidosis of man. Vestn Dermatol Venereol 1963;38:34-42.

14. Forton F, Seys B. Density of Demodex folliculorum in rosacea: a case-control study using standardized skinsurface biopsy. Br J Dermatol 1993;128:650-9.

15. Aşkin U, Seçkin D. Comparison of the two techniques for measurement of the density of Demodex folliculorum: standardized skin surface biopsy and direct microscopic examination. $\mathrm{Br} \mathrm{J}$ Dermatol 2010;162:1124-6.

16. Sakuntabhai A, Timpatanapong P. Topical steroid induced chronic demodicidosis. J Med Assoc Thai 1991;74:116-9.

17. Forton F, Song M. Limitations of standardized skin surface biopsy in measurement of the density of Demodex folliculorum. A case report. Br J Dermatol 1998;139:697-700.

18. Vargas-Arzola J, Reyes-Velasco L, Segura-Salvador A, Márquez-Navarro A, Díaz-Chiguer DL, NoguedaTorres B. Prevalence of Demodex mites in eyelashes among people of Oaxaca, Mexico. Acta Microbiol Immunol Hung 2012;59:257-62.

19. Moran EM, Foley R, Powell FC. Demodex and rosacea revisited. Clin Dermatol 2017;35:195-200.
20. Firat PY, Geçit İ, Depecik F, Karadan M, Karci E, Karaman Ü, et al. Demodex spp. positivity among laboratory staff, kitchen staff, cleaning workers and nurses working in a state hospital. Turkiye Parazitol Derg 2010;34:164-7.

21. Özdemir H, Özer E, Özdemir S, Alkanat M. The prevalance of demodex species in faculty of health science students. Türkderm 2015;49:139-41

22. Karaman Ü, Kolören Z, Enginyurt Ö, Özer A. The epidemiology of demodex mites at the college students living in dormitories in the city of Ordu. Turkiye Parazitol Derg 2014;38:166-71.

23. Durmaz S, Erkan Yula E, Kaya ÖA, Gökmen AA, Kılınç Ç, Atambay M, et al. Sociodemographic characteristics of patients with Demodex brevis and Demodex folliculorum infestation and its association with rosacea and Behçet?s disease. Biomedical Research 2015;26: 549-55

24. Erbağci Z, Ozgöztaşi O. The significance of Demodex folliculorum density in rosacea. Int $\mathrm{J}$ Dermatol 1998;37:421-5.

25. Demirdağ HG, Özcan H, Gürsoy Ş, Beker Akbulut G. The effects of sebum configuration on Demodex spp. density. Turk J Med Sci 2016;46:1415-21.

26. Miman Ö, Şimşek K, Özselçuk S, Küçükkoçak E, Karaca Ş. Üniversite Öğrencilerinde Demodex Sp. Yayggınlığının Araştırılması.The Medical Journal of Kocatepe 2008;9:37-39.

27. Tilki E, Zeytun E, Doğan S. Prevalence and Density of Demodex folliculorum and Demodex brevis (Acari: Demodicidae) in Erzincan Province. Turkiye Parazitol Derg 2017;41:80-6.

28. Zeytun E, Tilki E, Doğan S, Mumcuoğlu KY. The effect of skin moisture, $\mathrm{pH}$, and temperature on the density of Demodex folliculorum and Demodex brevis (Acari: Demodicidae) in students and staff of the Erzincan University, Turkey. Int $\mathrm{J}$ Dermatol 2017;56:762-6.

29. Kaplan M, Keleştemur N, Başpınar S. Demodex spp. Prevalence among University Students. Kafkas Univ Vet Fak Derg 2012;18:A43-A46.

30. Rufli T, Mumcuoglu Y. The hair follicle mites Demodex folliculorum and Demodex brevis: biology and medical importance. A review. Dermatologica 1981;162:1-11.

31. Madeira NG, Sogayar MI. The prevalence of Demodex folliculorum and Demodex brevis in a population sample from Botucatu, São Paulo, Brazil. Rev Soc Bras Med Trop 1993;26:221-4.

32. Lacey N, Kavanagh K, Tseng SC. Under the lash: Demodex mites in human diseases. Biochem (Lond) 2009;31:2-6.

33. Lacey N, Russell-Hallinan A, Zouboulis CC, Powell FC. Demodex mites modulate sebocyte immune reaction: possible role in the pathogenesis of rosacea. Br J Dermatol 2018;179:420-30.

34. Akilov OE, Mumcuoglu KY. Immune response in demodicosis. J Eur Acad Dermatol Venereol. 2004;18:440-4. 
35. Kulac M, Ciftci IH, Karaca S, Cetinkaya Z. Clinical importance of Demodex folliculorum in patients receiving phototherapy. Int J Dermatol 2008;47:72-7.

36. Akilov OE, Mumcuoglu KY. Association between human demodicosis and HLA class I. Clin Exp Dermatol 2003;28:70-3.

37. Sparks JA. Rheumatoid Arthritis. Ann Intern Med 2019;170:ITC1-ITC16.

38. Chua-Aguilera CJ, Möller B, Yawalkar N. Skin Manifestations of Rheumatoid Arthritis, Juvenile Idiopathic Arthritis, and Spondyloarthritides. Clin Rev Allergy Immunol 2017;53:371-93.
39. Chen SY, Wang HH. The relationship between physical function, knowledge of disease, social support and self-care behavior in patients with rheumatoid arthritis. J Nurs Res 2007;15:183-92.

40. Katchamart W, Narongroeknawin P, Chanapai W, Thaweeratthakul P. Health-related quality of life in patients with rheumatoid arthritis. BMC Rheumatol 2019;3:34.

41. Yazısız H, Çekin Y, Koçlar FG. The Presence of Demodex Mites in Patients with Dermatologic Symptoms of the Face. Turkiye Parazitol Derg 2019;43:143-8. 